\title{
A PAISAGEM VISTA COMO CULTURA, UMA HERANÇA A SER AS- SEGURADA AS FUTURAS GERAÇÕES: CONCEITOS, APLICAÇÕES E SUBSÍDIOS A GESTÃO AMBIENTAL
}

José Antônio de Sousa ${ }^{1}$

\begin{abstract}
Resumo
Este artigo tem como objeto de estudo a Paisagem Cultural, onde num primeiro momento procuramos ilustrar os conceitos de paisagem cultural entrelaçada à ciência geográfica a partir de algumas ideias clássicas de Milton Santos, as recentes discussões do Patrimônio Natural como do Arquiteto Carlos Fernando Moura Delphim, o Iphan e a legislação pertinente, no intuito de refletir acerca das políticas de enquadramento de áreas enquanto Paisagem Cultural, acreditando que oferecem subsídios no gerenciamento da gestão e preservação ambiental. A discussão se faz necessária com a exposição das inter-relações entre cultura, meio ambiente. Na segunda parte discutimos a lógica da gestão compartilhada, enquanto relação política, ética e de postura cuja tomada de decisão não poderá dissociar a natureza e a cultura. Subentende-se que a relação denominada de pacto, cujos mecanismos ocorrem entre poder público, sociedade civil e iniciativa privada, fruto do processo harmônico no planejamento e construção de políticas sociais, visando integrar e desenvolver a cultura preservacionista. Porém algumas interfaces são apontadas como problemas de ordem socioeconômica, estrutural, e podem ser vislumbrados a partir dos conflitos sociais entre preservação e desenvolvimento, do jogo de interesses econômicos, das relações de poder presentes em nossos dia a dia, entraves originados via sistema econômico capitalista que cria uma cultura dominante em detrimento do capital cultural, cujos valores simbólicos, biológico, afetivo do meio ambiente e das manifestações culturais presentes, por exemplo, nas paisagens se processam nas interações entre homem e natureza, muitas vezes são desprezados.
\end{abstract}

Palavras-chave: Paisagem Cultural; Meio Ambiente; Gestão Compartilhada.

\begin{abstract}
This article has as its object of study the cultural landscape, which at first tried to illustrate the concepts of cultural landscape intertwined with geographical science from some classical ideas of Milton Santos, recent discussions and the $\mathrm{Na}$ tural Heritage Architect Carlos Fernando Moura Delphim, Iphan and relevant legislation in order to reflect on the political framing areas as Cultural Landscape, believing that provide subsidies in managing the management and environmental preservation. The discussion is required with the exposure of the interrelationships between culture, environment. In the second part we discuss the logic of shared management, while political relations, ethics and attitude which decision making can not separate nature and culture. It is understood that the relation called pact, whose mechanisms occur between government, civil society and the private sector, due to the harmonic process in the planning and construction of social policies aiming to integrate and develop the culture preservationist.


However, some interfaces are identified as problems in the socioeconomic, structural, and can be glimpsed from the social conflicts between preservation and development of the game of economic interests, power relations present in our day to day obstacles originated via capitalist economic system which creates a dominant culture at the expense of cultural capital, whose symbolic values, biological, affective environment and cultural manifestations present, for example, the landscapes are processed in interactions between man and nature, are often neglected. nderstand the intrinsic relationships the fight greenwashing practices and Environmental Education.

Keywords: Cultural Landscape; Environment; Shared Management. 


\section{Apresentação}

O estudo e definição da Paisagem Cultural é um dos mais novos conceitos de preservação do Patrimônio Natural no Brasil, regulamentado pela portaria no ${ }^{\circ} 127$ de 2009 que institui a chamada "chancela da paisagem". Este trabalho procura destacar a importância deste instrumento, no gerenciamento de políticas de gestão e preservação ambiental, aliada ao aspecto cultural, no processo de definição e declaração das paisagens culturais e o seu acautelamento. Como iremos ver a paisagem cultural é definida a partir de uma porção peculiar, espaço territorial que concentra a materialidade. Portanto essa portaria é um potencializa a consciência na conservação ambiental, frente aos demais instrumentos, tais como declarações, tombamentos e inventários.

O conceito de paisagem é amplo. Segundo Milton Santos em "A Natureza do espaço: Técnica e Tempo, Razão e Emoção" buscando compreender as distinções entre paisagem e espaço e suas epistemologias, seria um "conjunto de formas que, num dado momento, exprimem as heranças que representam as sucessivas reações localizadas entre homem e natureza", cada uma dessas formas para Santos é o espaço. Observamos nos estudos de Santos que o conceito de paisagem está atrelado e muito recorrente as questões relacionadas ao território, onde a "paisagem compõe um conjunto de elementos naturais e artificiais que fisicamente caracterizam uma área" (SANTOS, 2006, p.66). Corroborando com C. Reboratti (2006, p. 17) "a paisagem humana é uma combinação de vários tempos presentes" o que nos leva a interpretar o seu caráter dinâmico e transformacional da ação humana ao longo de gerações, onde o espaço é a amostra concreta das mudanças, essa interpretação é complexa e por vezes são analisados os fatores das técnicas, práticas e modalidades, cujas recorrências são captadas e classificadas para estudos e mensurações.

A paisagem segundo Santos passou a ser objeto de estudo, conceituação e contemplação de uma maneira mais concreta com as expressões artísticas em diversos campos como a pintura renascentista e a fotografia com suas produções em massa. "com a arte da pintura, a partir da composição da perspectiva no Renascimento, que se conformou definitivamente a transformação de uma visão mais concreta da natureza em percepção sensível ou em processo seletivo de apreensão da realidade. (SANTOS, 2006).

Dessa foram compreende-se em parte as inter-relações homem natureza trabalhadas por Milton Santosna perspectiva do conceito de paisagem espaçoeterritório. Essas vertentes são trabalhadas de modo interdisciplinar, ou seja, abordando o capitalismo via marxismoparacompreenderalógicadamaterialidadedapaisagem, sejaemquestõesfilosóficasquandoprocuraentenderaintangibilidadeda essência criadoradaspaisagens.

Ainda nos detendo sobre conceitos gerais aplicados a paisagem natural e cultural, homem e meio ambiente, muito se fala sobre a política dos lugares e dos espaços cujas questões se bifurcam para uma gama de temas complexos na relação homem-natureza. O Instituto do Patrimônio Histórico Artístico e Nacional - IPHAN é a autarquia do governo brasileiro que muito embora seja o articulador da portaria 127/2009 não é o único responsável pela chancela da paisagem, mas sim está calcando num pacto gestor envolvendo outras instâncias e instituições. A portaria nos apresenta uma definição de Paisagem Cultural como: "Uma porção peculiar do território nacional, representativa do processo de interação dohomem com o meio natural" (IPHAN,2009, 
p. 35). Um dos especialistas no assunto com seus trabalhos práticos de restauração no Jardim Botânico do Rio de Janeiro na década de 1970, o arquiteto de paisagem Carlos Fernando de Moura Delphim, vem difundindo esse conceito no Brasil como Coordenador-Geral do Patrimônio Natural do IPHAN e como Consultor da UNESCO para preservação do Patrimônio Natural brasileiro, com atuação em preservação de jardins, passeios públicos e praças pelo IPHAN, atualmente vem tendo um papel importante na difusão da chancela da paisagem, a exemplo do caso das paisagens cariocas. Delphim trabalha juntamente a outros profissionais como os arquitetos Marta Queiroga Amoroso Anastácio, Sérgio Martins Treitler (In memória) técnicos do IPHAN.

Para Delphim em "O Patrimônio Natural do Brasil" a paisagem:

Resulta de um somatório de diferentes elementos, das formas como se inter-relacionam, de informações complexas, de inúmeras formas de percepção isoladas, de visões analíticas (...). Envolve questões físicas, atuais ou pretéritas, a gênese de aspectos como a formação geológica e geomorfológica, a diversidade de formas de relevo, a compartimentação geográfica e hidrológica, registros de acontecimentos paleoclimáticos e vegetacionais de capital importância para o conhecimento da história do planeta, marcas deixadas por povos pré-históricos (...) os efeitos provocados pelas ações do homem moderno. (DELPHIM, 2005, p. 03)

Como se nota no trecho acima os subsídios em que a interpretação da paisagem pode nos oferecer a preservação da vegetação, relevos, partes hidrográficas entre outros aspectos naturais intrínsecos e as marcas do homem na paisagem são diversos. Na Bahia após o tombo pelo IPAHN do Morro do Pai Inácio no município de Palmeiras e a Gruta da Mangabeira localizada no município de Ituaçu, com consultorias de Delphim observa-se que a preservação ambiental, o quesito consciência e desenvolvimento econômico social melhorou consideravelmente, pois esses lugares aumentaram seus graus de valorização tornando-os emblemáticos na região. Outros elementos como os rios, várzeas, veredas, trechos de ferrovias e remanescentes de biomas como cerrado, caatinga tem sido pauta de recentes colóquios sobre paisagem cultural a exemplo dos compromissos da Carta de Vitória sobre a preservação de propriedades rurais pomeranas e da Carta de Pirapora sobre a preservação de bens culturais e o pedido de inclusão do Rio São Francisco na lista do patrimônio mundial, momento também de apresentação da portaria IPHAN no 450/2011 que dispões sobre a composição de grupos de trabalho para tratar do Patrimônio Cultural do Rio São Francisco. Na pauta destas cartas e legislações ficam evidentes que o patrimônio material e imaterial erigido em determinados lugares, constroem e fundamentam, portanto as paisagens como produto de identidade histórico-cultural das cidades.

Entre as questões centrais apontadas por Delphim encontra-se o próprio conceito de paisagem, a história das paisagens, as categorias de paisagem como patrimônio natural, seus mecanismos de proteção da através da legislação, bem como a sensibilização e interpretação dos lugares, onde são apontaficada tanto como "posturas de cunho ético e pragmático" (DELPHIM, 2005, p. 02), consciência e necessidade resumem basicamente suas ideias. 
Fazendo um contraponto entre os limites e problemas que há com a ideia da interpretação e chancela da paisagem cultural é interessante à proposta de análise "O patrimônio e as paisagens: novos conceitos para velhas concepções?" de Vanessa Gayego Bello Figueiredo quando chama nossa atenção para com os perigos que há no interesse econômico, quando as paisagens são encaradas como produto. Segundo ela problema reside no "sujeito moderno, ao toque do consumo descartável, passa a ter uma relação ainda mais fugaz com a natureza, transformando-a em artefato não reciclável, modificando intensamente os ciclos naturais, e, consequentemente, as paisagens" (FIGUEIREDO, 2012, p.03). Onde "Essa noção de natureza se contrapõe à ideia mais corrente de paisagem - a imagem processada, interpretada, representada, construída, inventada, metafórica, simbólica e retórica da natureza ou do ambiente" (FIGUEIREDO, 2012, p. 02).

Nesse sentido poderão ocorrem jogos de interesses econômicos que levem a falsas interpretações, como criações pictóricas, apelo à imagem, a que devemos nos atermos na relação homem-natureza. Essas preocupações estão mencionadas na portaria 127/2009 no Capítulo VIII que trata do acompanhamento e revalidação da chancela da paisagem. (IPHAN, 2009, p. 37).

\section{Legislação e recomendação para preservação de paisagens culturais}

Muito embora as discussões sobre a conceituação e aplicação de mecanismos de proteção da paisagem sejam relativamente novas, há uma vasta legislação, e diversas medidas que estreitam nossas concepções e sua contextualização no cenário atual sobre as políticas de Paisagem Cultural e suas considerações. Assim é preciso nos reportar a uma releitura e reflexão sobre a organização e decretação de importantes documentos históricos internacionais como cartas, convenções, declarações, recomendações por considerar seu teor de caráter universal, cosmopolita e grosso modo como influência na construção de tal política da pelas nações uma vez que se configuram como documentos norteadores de questões basilares.

Na coletânea "Cartas Patrimoniais" organizado por Isabelle Cury, encontramos uma síntese desses documentos internacionais. Destacaremos as convenções da UNESCO e a contribuição de alguns especialistas para ilustrar o título proposto. Foram importantes os comitês da Organização das Nações Unidas para a educação, à ciência e a cultura - UNESCO com intensas discussões. O primeiro comitê que selecionamos é a "Declaração de Estolcomo" na Suécia, ocorrida em junho de 1972 que tratou do ambiente humano e geraram os vinte e três princípios sobre a questão, tais como: direitos, deveres e garantias fundamentais do homem a um ambiente saudável e a qualidade de vida. No principio dois fazem uma listagem sobre os tipos de recursos naturais e seus ecossistemas e pedem que sejam preservados para esta e futuras gerações. Entre outros pontos trados nesses princípios estão conhecimento de causa de fatores de degradação e controle desses fatores, os mecanismos de desenvolvimento econômico e sua relação com a preservação do meio ambiente, o reconhecimento de problemas decorrentes dos desastres naturais, direito internacional e as políticas ambientais. 
flora e a fauna, e, especialmente, parcelas representativas dos ecossistemas, naturais, devem ser preservados em benefício dasgeraçõesatuaisefuturas, medianteum cuidadoso, planejamentoouadministraçãoadequados. (CURY,2004,p.171-172)

A seguir estruturou-se na $17^{a}$ Conferência Geral uma Convenção sobre a salvaguarda do patrimônio mundial, cultural e natural em Paris no ano de 1972, onde diversos países apresentaram seus planos para a preservação da natureza, aliada aos seus aspectos culturais. Interessa-nos nessa discussão pontuar o seu primeiro capítulo sobre a definição do Patrimônio Natural. No Artigo segundo onde focaliza nosso objeto conforme trecho transcrito abaixo:

Para fins da presente convenção serão considerados patrimônio natural: Os monumentos naturais constituídos por formações físicas e biológicas (...) do ponto de vista estético e científico, as formações geológicas e fisiográficas e as zonas nitidamente delimitadas que constituem o habitat de espécies de animais e vegetais ameaçados (...). Os sítios naturais ou zonas naturais, do ponto de vista da ciência da conservação ou da beleza natural, onde caberá ao Estado identificar e delimitar os diferentes bens mencionados neste artigo e situados em seu território. (CURY, 2004, p. 179)

Observa-se claramente que essas zonas citadas na convenção da UNESCO são alvos de delimitação e são conhecidas entre nós por diversas denominações entre elas as Unidades de Conservação tema central de discussão no Fórum Públicas, Territorialidade e Conflitos Socioambientais em Unidades de Conservação, proposto pelo Grupo de Estudos e Pesquisa Processos Identitários e Poder - GEPPIP da Universidade Federal de Sergipe- UFS de grande relevância para a evolução dos debates na atualidade. Onde o território é interpretado com o território com a criação da Área Preservação Ambiente Cultural - APAC e são poucas ainda no Brasil, dadas as proporções do seu território e o número de habitantes por metros quadrados em áreas de preservação.

O ano de 1992 vai marcar a introdução do conceito e a institucionalização do instrumento da Paisagem Cultural como um dos mais novos mecanismos de preservação do patrimônio cultural categorizando o aspecto natural na convenção da UNESCO realizada em Lapetit Pierre, também na França, desencadeando suas práticas de uma maneira mais efetiva e gerando a construção paulatina da lista do patrimônio mundial que conhecemos hoje.

Destacamos a "Recomendação n R-(95) 9" sobre a "Conservação integrada das áreas de paisagens culturais como integrantes de políticas paisagísticas" proferida pelo Conselho da Europa e o Comitê de ministros, em sua releitura escrevemos aqui as considerações que pensamos ser pertinentes ao nosso objeto de estudo e que auxiliam em nossa discussão e objetivos. A recomendação em primeiro lugar reafirma os ideais de outros comitês como a Convenção de Paris e a Carta do Rio, incorporando o aspecto da herança tanto cultural como natural, sendo visível cada vez mais a constatação dos ministros do presente conselho que expressam suas preocupações com a memória e a 
identidade de povos, suas comunidades, é um documento com importantes definições sobre a ideia da conservação, processo de identificação e avaliação de áreas com paisagem natural, implementação de políticas de paisagem, treinamento e pesquisa entre outras demandas, que podem ser interpretadas como "medidas operacionais em diversos campos da ciência". Em seu Artigo $4^{\circ}$ expressa a competência dos campos da arqueologia, geografia, planejamento urbano, história, agronomia, economia, ecologia, em "áreas de paisagem cultural" define o termo como sendo "partes especificas, topograficamente delimitadas da paisagem, formadas por várias combinações de agenciamentos naturais e humanos e ilustra a evolução da sociedade" (Cury, 2000, p. 335).

A paisagem é definida, caracterizada da maneira pela qual determinado território é percebido por um individuo ou comunidade (...) testemunho ao passado e ao presente do relacionamento existente entre os indivíduos e seu meio ambiente (...) ajuda a especificar culturas locais, sensibilidades, práticas crenças e tradições. (CURY, 2000, p. 331/332)
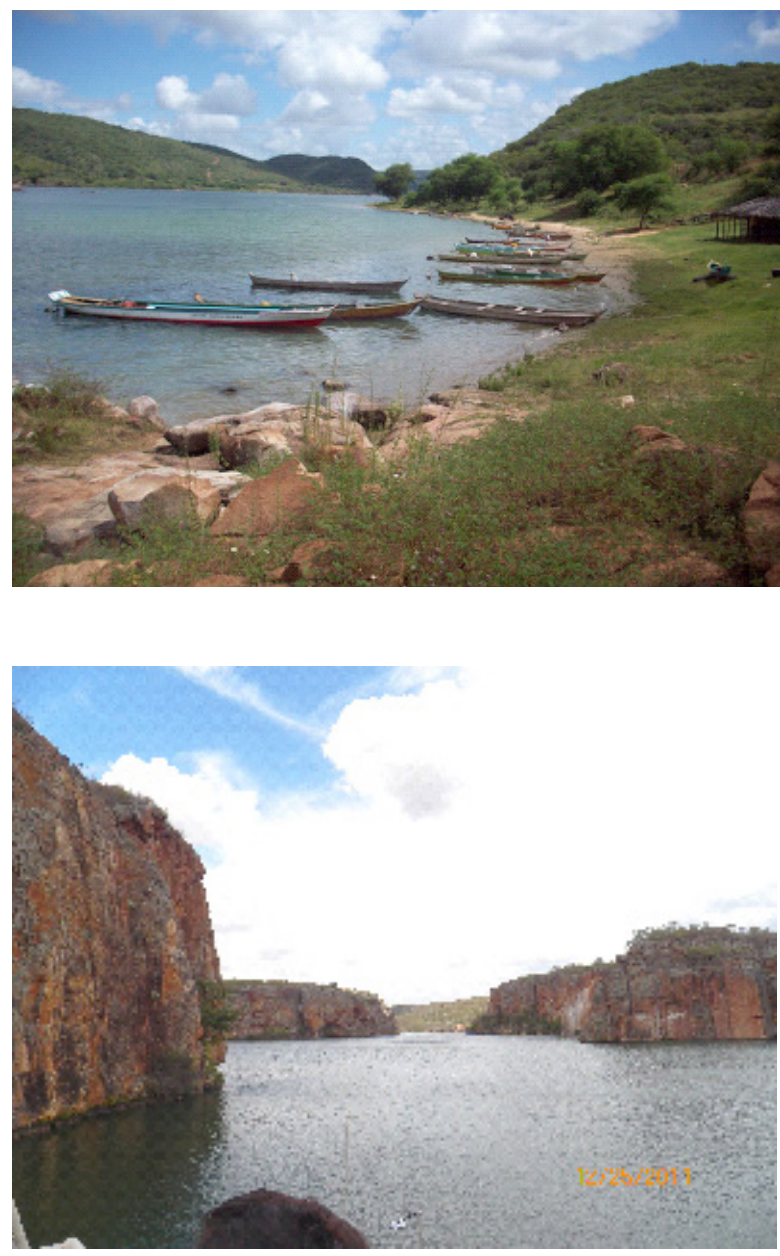

Ilustrações 01 e 02- Regioões ribeirinhas e paredões do Rio São Francisco 
A abordagem da publicidade anterior trazia termos mas condizentes com o produto uma vez que este de fato não é " $100 \%$ ecológico" , mas sim "biodegradável” . No entanto a abordagem atual traz no verso a mensagem é enfática:

[...] já nasceu ecológico, pois quando descartado volta para a natureza em seu estado original, como minério de ferro, sem deixar resíduos no meio ambiente. Além disto, sua embalagem plástica é totalmente reciclável [...]. (EMBALAGEM DE PRODUTO, 2010).

Observa-se assim que abordagem publicitária não considera os resíduos do processo produtivo, bem como os impactos da extração do minério de ferro. Uma vez descartado seria impossível o produto voltar à natureza "[...] em seu estado original" como prometido. Assim a utilização dos termos eco, natural, natura, verde, Green, bem como nomes de instituições beneficentes tem sido amplamente divulgado em embalagens com vistas a apresentar benefícios a produtos e serviços. Torna-se inclusive difícil para o consumidor observar o que faz parte das informações relativas à rotulagem e aquelas relativas à publicidade. $O$ exemplo da embalagem a seguir deixa evidente a confusão de terminologias.

Esses documentos internacionais nos ajudam a refletir sobre a política paisagística, à medida que essas definições, recomendações e constatações refletem do campo da cultura para o gerenciamento ambiental de áreas de conservação. Nestas recomendações, convenções e cartas ficam evidentes os interesses gerais em salvaguardar do ponto de vista legal e daí pontuamos a chancela da paisagem instituída no Brasil em 2009 através da portaria do Iphan $n^{\circ}$. 127. Essas cartas apresentadas a nós soam como medidas apropriadas como a qualificação técnicas para atuar na preservação e em especial nos fatores ecológicos, estéticos, culturais, econômicos e sociais de determinados territórios. Estes fatores são cruciais, nas diretrizes da área, onde perguntas e respostas em meio a um cenário carreado de contradições ora de deterioração, poluição visual visto por tanto nas preocupações da iminência da destruição via sistema econômico capitalista, onde algumas conquistas emergem como sinal de resistência, pois o sistema econômico do capitalismo em suas nuances tendem a acelerarem essa degradação em meio aos processos globais, ameaçando a continuidade das paisagens num processo acelerado. O Conselho Europeu através da "Recomendação no R-(95) 9" reafirma compromissos de outras cartas de que é preciso construir uma "política paisagística" Após fazer uma série de constatações e definição de pontos cruciais, lista grandes fenômenos que vem provocando impactos na paisagem como o uso insustentável dos recursos naturais, desenvolvimento descontrolado da indústria, técnicas e práticas de produção agrícola, silvícola desenvolvimento urbano sem planejamento, turismo e lazer os quais tem o efeito de modificar e ameaçar a existências de paisagens culturais (Cury, 2000, p. 330).

Com visto até aqui muito embora os conceitos acima apresentados são alvos de discussões desde a década de 1970 no âmbito dos comitês da UNESCO, a paisagem passou a ser alvo de uma proteção mais eficaz após a convenção em Lapetit Pierre em 1992 e atuação do Conselho Internacional de Monumentos e Sítios - ICOMOS, ano que marca a criação da lista mundial de paisagens e sítios naturais que passaram a serem reconhecidos legalmente como patrimônio natural. De lá para cá o conceito de 
preservação natural ganhou adeptos em várias partes do mundo, como Itália, Espanha, França, México, cujos relatos de experiências têm demonstrado motivações e qualidade de vida das populações envolvidas direta e indiretamente no entorno, região, cidade onde contém essas paisagens. O Brasil ainda caminha timidamente rumo a consolidação dessa área, pois os estudos para processos de preservação e seu processo de institucionalização nacional é embrionário, como com muitas candidaturas institucionalização e proteção das paisagens culturais a nível nacional que vem sendo organizadas a partir das portarias e chancela de proteção da paisagem. O Brasil é signatário dos documentos internacionais apresentados aqui a partir portaria do Iphan $n^{\circ} 127 / 2009$. Sua aplicação efetiva-se enquanto instrumento político-jurídico de processo administrativo da chancela.

\begin{tabular}{|c|c|c|c|}
\hline \multicolumn{4}{|c|}{$\begin{array}{c}\text { Lista dos monumentos paisagísticos e naturais } \\
\text { brasileiros na lista mundial }\end{array}$} \\
\hline Denominação & Categoria do bem & $\begin{array}{l}\text { Ano da inscri- } \\
\text { ção }\end{array}$ & Localização \\
\hline $\begin{array}{l}\text { Parque Nacional do } \\
\text { Iguaçu }\end{array}$ & Natural & 1986 & Paraná \\
\hline $\begin{array}{l}\text { Reservas da Mata } \\
\text { Atlântica da Costa do } \\
\text { Descobrimento }\end{array}$ & Natural & 1999 & $\begin{array}{l}\text { Bahia / Espírito } \\
\text { Santo }\end{array}$ \\
\hline $\begin{array}{l}\text { Parque Nacional do } \\
\text { Pantanal }\end{array}$ & Natural & 2000 & $\begin{array}{l}\text { Mato Grosso e } \\
\text { Mato Grosso do } \\
\text { Sul }\end{array}$ \\
\hline $\begin{array}{l}\text { Parque Nacional do } \\
\text { Jaú }\end{array}$ & Natural & 2000 & Amazonas \\
\hline $\begin{array}{l}\text { Ilhas Atlânticas de } \\
\text { Fernando de Noro- } \\
\text { nha e Atol da Rocas }\end{array}$ & Natural & 2001 & $\begin{array}{c}\text { Pernambuco e } \\
\text { Rio Grande do } \\
\text { Norte }\end{array}$ \\
\hline $\begin{array}{c}\text { Parque Nacional da } \\
\text { Chapada Dos Veadei- } \\
\text { ros e Parque Nacional } \\
\text { das Emas }\end{array}$ & Natural & 2001 & Goiás \\
\hline
\end{tabular}

Tabela 01 - Lista do Patrimônio Natural Brasileiro da humanidade 

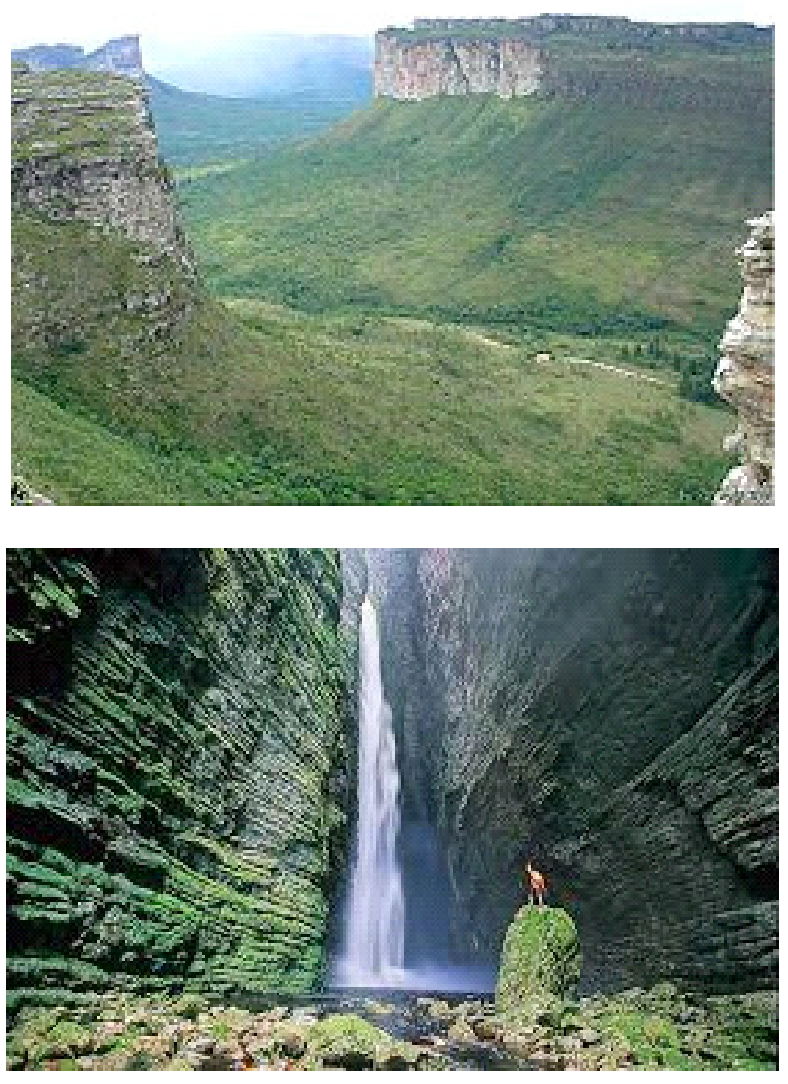

Ilustrações 03 e 04 - Paisagens da Chapada Diamantina - BA, Fonte: Cultura Bahia.com. 


\begin{tabular}{|c|c|c|c|}
\hline \multicolumn{3}{|c|}{ Lista do Patrimônio Cultural Brasileiro da Humanidade } \\
\hline Denominação & Categoria do bem & Ano da inscrição & Localização \\
\hline $\begin{array}{c}\text { Cidade histórica de } \\
\text { Ouro Preto }\end{array}$ & Cultural & 1980 & Minas Gerais \\
\hline $\begin{array}{c}\text { Missões Jesuíticas } \\
\text { Guarani e Ruínas São } \\
\text { Miguel das Missões }\end{array}$ & Cultural & $1983 / 84$ & $\begin{array}{c}\text { Rio Grande do } \\
\text { Sul / Argentina }\end{array}$ \\
\hline $\begin{array}{c}\text { Centro Histórico de } \\
\text { Salvador }\end{array}$ & Cultural & 1985 & Bahia \\
\hline $\begin{array}{c}\text { Santuário de Bom } \\
\text { Jesus de Matosinhos }\end{array}$ & Cultural & 1985 & Minas Gerais \\
\hline $\begin{array}{c}\text { Plano Piloto de } \\
\text { Brasilia }\end{array}$ & Cultural & 1987 & Brasília \\
\hline $\begin{array}{c}\text { Parque Nacional da } \\
\text { Serra da Capivara }\end{array}$ & Cultural & 1991 & Miauí \\
\hline $\begin{array}{c}\text { Centro Histórico de } \\
\text { São Luís }\end{array}$ & Cultural & 1997 & Maranhão \\
\hline $\begin{array}{c}\text { Centro Histórico de } \\
\text { Diamantina } \\
\text { ciscoiás }\end{array}$ & Cultural & 1999 & 2001 \\
\hline $\begin{array}{c}\text { Centro Histórico de } \\
\text { Praça de São Fran- }\end{array}$ & Cultural & & \\
\hline
\end{tabular}

Tabela 02 - Lista do Patrimônio Cultural Brasileiro da humanidade

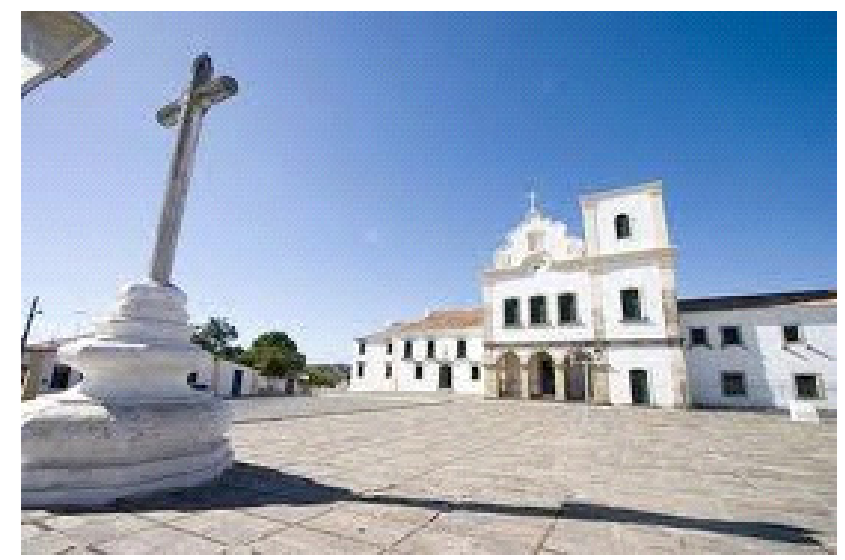




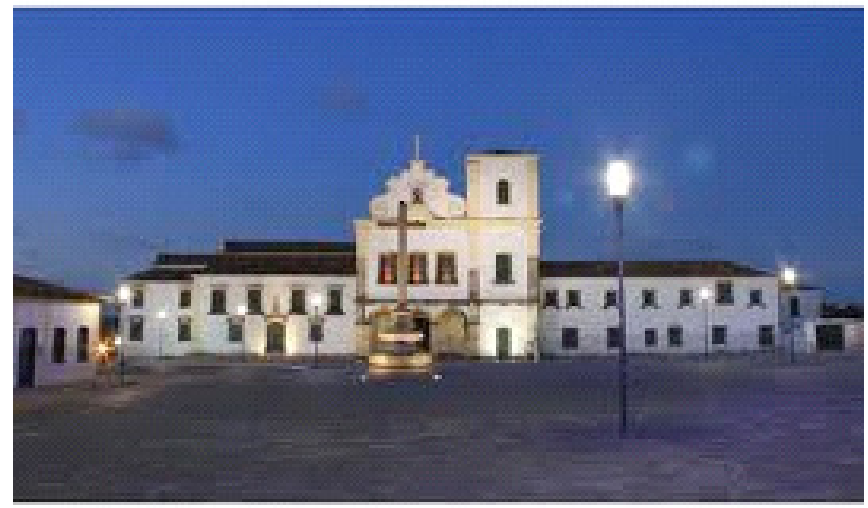

Ilustrações 05 e 06 - Praça de São Francisco, São Cristovão Sergipe.

Fonte: casacivil.se.gov.br

\section{O capitalismo como problema de ordem estrutural na preservação ambiental e cultural}

É necessária uma reflexão sobre o sistema econômico capitalista que cria uma cultura dominante em detrimento do capital cultural, dos valores simbólicos, biológicos e afetivos do meio ambiente e das manifestações culturais, os quais se processam nas interações entre homem e natureza, onde o aspecto da paisagem cultural apresenta-se como mais um instrumento de preservação. Assim e como base nas proposições das cartas patrimoniais delineamos algumas questões latentes observadas na literatura analisada, a serem refletidas e discutidas sobre a preservação da paisagem cultural e os subsídios gestão ambiental. Muito se fala na importância do diagnóstico dos fatores e causas da degradação ambiental e cultural, fiscalização, inclusão social a partir de projetos oriundos da sociedade civil, como medidas de conservação preventiva aplicado nas paisagens na relação homem-natureza. Fazem-se necessário o reconhecimento da importância da gestão democrática, dos antagonismos que há entre preservação e desenvolvimento gerados pela cultura do sistema capitalista, que resulta em conflitos sociais resultantes da discrepância de renda, emprego, marginalização e violência.

Sendo assim é preciso uma política mais eficaz de valorização estratégica voltada às áreas e Unidades de conservação - UCS, regidas pela lei nº. 9.985/2000 enquanto zonas territoriais tradicionais potenciais e as demandas emergentes pela delimitação de novas áreas de preservação, detentoras de paisagens culturais passíveis de preservação a título de exemplo citamos o Pantal do Mato Grosso, a Chapada Diamantina, o Vale do Rio São Francisco e tantas outras que se encontram em processo de análise.

\section{Gestão compartilhada, uma palavra de ordem na preservação}

Como visto nos debates e proposições dos documentos internacionais o processo acelerado de industrialização, as práticas agrícolas e tantas outras ações antrópicas provocadas pelo homem moderno a exemplo das suas práticas de consumo descartável muitas vezes inconsciente, passam a ter uma relação ainda mais direta e consequentemente as paisagens, a exemplo também das atividades turísticas 
Por outro lado e em conjunto, os desastres naturais tem representado uma série de problemas relacionados à degradação aos recursos naturais, por estas e outras questões relacionadas ao universo da gestão cultural e ambiental acreditamos ser fundamental refletir e discutir a lógica da gestão compartilhada entre cultura e meio ambiente perante a atuação dos órgãos de preservação e instrumentos em suas respectivas áreas, pois é uma relação política, ética e de postura cuja tomada de decisão não poderá dissociar a natureza e a cultura, onde subentende-se a relação entre poder público, sociedade civil e iniciativa privada e sua harmonia. Observa-se a crescente participação da sociedade civil em projetos socioculturais descentralizadores, o que significa um avanço no compartilhamento e democratização na participação social. Porém é um tema que ainda precisa ser muito debatido, pois muitas práticas da velha administração persistem e povoam a mentalidade de gestores na forma pela qual a organização e aplicação de políticas por parte de determinados órgãos são deliberados. Muitos destes problemas citados aqui têm suas interfaces e apontam problemas de ordem socioeconômica, estrutural, vislumbrados a partir dos chamados conflitos sociais no jogo de interesses econômicos e as relações de poder presentes em nosso dia a dia na relação entre preservação e desenvolvimento, considerados entraves na preservação.

\section{Considerações Finais}

Procuramos aqui fazer uma incursão, exposição e discussão sobre as atuais políticas de salvaguarda das paisagens naturais, cultuais no Brasil na ótica do conceito de paisagem cultural e patrimônio natural e a sua interligação com o universo da gestão democrática, buscando um diálogo e apresentando subsídios ao ambiente via unidades de conservação, ao passo que tal diálogo poderá estreitar as reflexões sobre a lógica da preservação via conceito de gestão compartilhada, como está preconizada nas convenções da UNESCO, nas recomendações do Conselho da Europa, na Declaração de Estolcomo entre outros. Vimos também à discussão da política paisagística partindo de conceituações e suas implicações a preservação do meio ambiente como as ideais de Milton Santos, Carlos Fernando de Moura Delphim e a importância do Iphan da aplicação da política brasileira de preservação da paisagem com o instrumento da chancela e o perigos que há quando encaradas meramente como produto de capitalização.

\section{Referências}

BRASIL. Instituto do Patrimônio Histórico e Artístico Nacional (IPHAN). Portaria $\mathrm{n}^{\circ} .450$, de 20 de dezembro de 2011. Dispõe sobre a criação de Grupos de Trabalho para tratar do Patrimônio Cultural do Rio São Francisco e dá outras providências. Diário Oficial da República Federativa do Brasil - Seção I, nº 244, 21 de dezembro de 2011. 
CONSELHO DA EUROPA, Recomendação n $\mathrm{R}(95) 9$ Sobre a conservação integrada das áreas de paisagens culturais como integrantes das políticas paisagísticas. Comitê de Minsitros, 543a Encontro de Vice-Ministros em 11 de setembro de 1995. In: CURY, Isabelle (org). Cartas Patrimoniais. Rio de Janeiro: IPHAN, Edições do Patrimônio, 2004, p.329-345. Edições do Patrimônio.

DELPHIM, Carlos Fernando de Moura. O Patrimônio natural do Brasil. Disponível em: http://www.iphan.gov.br/textosespecialidos Acesso em: abril de 2013.

FIGUEIREDO, Vanessa Gayego Bello. O patrimônio e as paisagens: novos conceitos para velhas concepções? In: Seminario de Paisajes Culturales Udelar/upc [Conpadre n.11/2012], 2, 2012, Montevideo [Uruguay]. Actas... Montevideo: Red Conpadre, 2012. p. 01-17. Disponível em: www.conpadre.org Acesso em abril de 2013.

ICOMOS. The World Heritage List: Filling the Gaps - an Action Plan for the Future. Munich: UNESCO, 2004. Disponível em: http://whc.unesco.org/ uploads/activities/documents/activity-590-1.pdf Acesso em: abril de 2013.

IPHAN, Instituto do Patrimônio Histórico e Artístico Nacional (Brasil). Cartas patrimoniais. Isabelle Cury (org.) 3. Ed. rev. e aum. Rio de Janeiro: IPHAN, 2004. Edições do Patrimônio.

Paisagem Cultural. Brasília: IPHAN, 2009.

SANTOS, Milton. A natureza do espaço. $4^{\mathrm{a}}$ Ed. 2a . Reimpr. São Paulo: Editora da Universidade de São Paulo, 2006. Coleção Milton Santos - 1

UNEP, Declaração sobre o ambiente humano. Assembleia Geral Das Nações Unidas Para o Meio Ambiente, reunida em Estocolmo de 5 a 16 de junho de 1972. In: CURY, Isabelle (org). Cartas Patrimoniais. Rio de Janeiro: IPHAN, Edições do Patrimônio, 2004, p.171-175. Edições do Patrimônio.

UNESCO, Convenção para a Proteção do Patrimônio Mundial - Reunião do grupo de peritos em paisagens culturais. da Organização das Nações Unidas para a Educação, a Ciência e a Cultura, 16 reunião, La Petite Pierre, França, outubro de 1992. Disponível em: <http://whc.unesco.org/en/culturallandscape/\#3> Acesso em: maio de 2013.

UNESCO, Convenção para a Proteção do Patrimônio Mundial, Cultural e Natural. Conferência Geral da Organização das Nações Unidas para a Educação, a Ciência e a Cultura, UNESCO, 17a sessão, Paris, 17 de outubro à 21 de novembro de 1972. In: CURY, Isabelle (org). Cartas Patrimoniais. Rio de Janeiro: IPHAN, Edições do Patrimônio, 2004, p.177-193. Edições do Patrimônio. 